ANUARIO DE ESTUdIOS MEDIEVALES

50/1, enero-junio de 2020, pp. 323-352

ISSN 0066-5061

https://doi.org/10.3989/aem.2020.50.1.12

\title{
NOVES PERSPECTIVES PER A UNA QÜESTIÓ NO RESOLTA: PER QUĖ CATALUNYA FOU UN PRINCIPAT I NO UN REGNE?
}

\author{
NEW PERSPECTIVES FOR AN UNRESOLVED QUESTION: \\ WHY WAS CATALONIA A PRINCIPALITY AND NOT A KINGDOM?
}

\author{
CRISTIAN PALOMO REINA \\ Universitat Autònoma de Barcelona \\ https://orcid.org/0000-0002-3593-2903
}

\begin{abstract}
Resum: En aquest article abordarem per què durant el període baixmedieval Catalunya esdevingué un principat. Temàtica que inevitablement s'incardina en el fet que el territori català no comptés oficialment amb la categoria política de 'regne' i que ens mena a revisar i qüestionar l'explicació canònica d'aquest fet, bastida pel medievalista Ramon d'Abadal fa més de mig segle. A continuació, oferim noves perspectives i hipòtesis a partir de la darrera historiografia que ha tractat el tema.
\end{abstract}

Paraules clau: principat de Catalunya; Ramon d'Abadal; regne; tractat de Corbeil; història conceptual.

Abstract: In this article the question of why Catalonia became a principality in the late medieval period will be discussed. It is an issue that inevitably involves the fact that the area of Catalonia did not officially have the political category of 'kingdom', which leads us to review and question the canonical explanation of this fact, developed by the medievalist Ramon d'Abadal more than half a century ago. Subsequently, new perspectives and hypotheses derived from the latest historical works to deal with the subject are offered.

Keywords: Principality of Catalonia; Ramon d'Abadal; kingdom; Treaty of Corbeil; conceptual history.

\section{SUMARI}

1. La problemàtica del concepte "principat" a la Catalunya medieval.- 2. Visió canònica de per què Catalunya no fou oficialment un regne. La concepció de Ramon d'Abadal.- 3. Una teoria basada en interpretacions historiogràfiques baixmedievals i altmodernes.- 4. Comtats dels segles IX-XIII a mode d'estats dels segles XIX i XX.5. Fets clau de les relacions francobarcelonines dels segles X-XII.- 6. El tractat de Corbeil.- 7. Hipòtesis sobre la manca d'un títol regi per a Catalunya.- 8. Conclusió.9. Bibliografia citada.

Copyright: (C) 2020 CSIC. This is an open-access article distributed under the terms of the Creative Commons Attribution 4.0 International (CC BY 4.0) License. 


\section{LA PROBLEMÀTICA DEL CONCEPTE "PRINCIPAT" A LA CATALUNYA MEDIEVAL}

En estudiar l'evolució històrica del concepte "principat" aplicat a Catalunya ${ }^{1}$, hem constatat l'existència d'una problemàtica historiogràfica que ha de ser revisada i debatuda.

Aquesta no té relació amb la seva etimologia, que prové clarament de la forma masculina del substantiu llatí principātus, que en l'Antiguitat significava "preeminència", "sobirania" o "poder", el qual, a la vegada, deriva de l'adjectiu princeps, -l̆pis, és a dir, "capdavanter" o "principal". Un mot, el de princeps que, a la Cristiandat, romangué íntimament associat de forma genèrica al poder sobirà dels monarques, arran del seu ús per part dels antics emperadors romans.

La problemàtica tampoc té a veure amb la documentació dels conceptes "príncep" i "principat" en l'àmbit català, que es poden resseguir des de les seves primeres aparicions fins al punt que "principat" quedà afermat com el títol polític oficial del conjunt territorial.

Així, durant els segles X i XI podem trobar de forma esporàdica princeps com a titulació honorífica no transmissible ni lligada a un territori, emprada per diversos comtes d'arreu de la pre-Catalunya ${ }^{2}$, tot i que amb el pas del temps és cada cop més acaparada pels comtes de Barcelona ${ }^{3}$. Tanmateix, el significat monàrquic d'arrel imperial del mot princeps rep una gran embranzida a les corts d'Europa amb l'arribada, en els segles XII, XIII i XIV, del dret d'arrel romana adaptat al món feudal. En el cas del nord-est de la península Ibèrica observem com, durant el regnat de Ramon Berenguer IV (1131-1162), el comte de Barcelona no dubtà a intitular-se princeps aragonensis com a solució per proclamar-se sobirà d'Aragó sense emprar el títol de rex ${ }^{4}$, mentre que en els Usatges de Barcelona -escrits en temps d'aquest comte o del seu fill, el rei Alfons I el Cast-, el comte barceloní és anomenat princeps i l'espai català on teòricament exerceix la seva autoritat pot ser anomenat ocasionalment principatum ${ }^{5}$.

\footnotetext{
${ }^{1}$ En la nostra tesi doctoral duguérem a terme una anàlisi històrica, quantitativa, semàntica i comparativa d'alguns conceptes politicojurídics i identitaris de la història baixmedieval i altmoderna de Catalunya. Aquesta investigació pogué ser confegida gràcies a l'ajut predoctoral FI-DGR de l'AGAUR, del qual vàrem gaudir entre el març de 2015 i febrer de 2018. Vegeu: Palomo 2018a.

${ }^{2}$ Salrach 2011.

${ }^{3}$ Vegeu un seguit d'exemples del segle XI a Cingolani 2008, pp. 154-156; 2015, pp. 101104 i 110.

${ }^{4}$ Sobre les titulacions efectives de Ramon Berenguer IV i el debat que hi ha al voltant: Palomo 2018b.

${ }^{5}$ Cingolani 2015, p. 143.
} 
Ja en el segle XIII, aquesta concepció romanista es va afermant en textos catalans cabdals del període com les Commemoracions, tradicionalment atribuïdes al jurista Pere Albert, o en el Llibre del rei en Pere d'Aragó e dels seus antecessors passats de Bernat Desclot. En el primer es pot advertir com Catalunya comença a prendre dimensió d'una res publica per la qual vetlla el sobirà a mode de princeps terrae ${ }^{6}$, mentre que en la crònica se'ns parla de l'usatge de Barcelona que obliga los hòmens de sa terra a ajudar al príncep de Catalunya, comte de Barcelona en la guerra ${ }^{7}$.

Nogensmenys, ben segurament el pas definitiu per a l'establiment de Catalunya com a "principat" tingué lloc l'any 1343, quan el rei d'Aragó Pere III el Cerimoniós, en el seu procés judicial contra el rei de Mallorca i comte de Rosselló i Cerdanya, no s'estigué d'identificar-se com a Príncep de Cathaluny $a^{8}$ i declarar sobre els comtats septentrionals que:

los dits comtats et terres són de, et dins, Cathalunya et del Principat de Cathalunya en lo qual nós, axí con a hereu universal d'aquell Senyor Rey En Jacme [I d'Aragó] per mijà de nostres predecessors Reys d'Aragó havem succeït et regnam [...] Rosselló tots temps sia estat dins les limitacions del Principat de Cathalunya, et axí u dien les leys et constitucions de la pàtria, ço es, que Cathalunya és de Montsó a Salses inclusive? .

En aquestes paraules del rei Pere hi ha una distinció entre "Catalunya" i el "principat de Catalunya". És prou clar que amb "Catalunya" el sobirà es referia als límits geogràfics de la terra catalana, mentre que amb "Principat" sembla al-ludir a Catalunya com a ens geopolític i monàrquic sobre el qual regnen i s'havien anat succeint el prínceps de Catalunya, o sigui, els reis d'Aragó i comtes de Barcelona fins arribar a Pere III.

En qualsevol cas, trenta-tres anys després, el 6 de setembre de 1376, en les Corts de Montsó, reunides per la defensa del principat de Catalunya en vista d'un atac de Lluís, comte de Provença i duc d'Anjou, s'exposa:

En nom de Déu. Sàpien tuyt que·l General de Cathalunya, ço és, los tres braçes del Principat de Cathalunya ajustats solempnament et constituïts en les Corts general(s), les quals lo senyor rey de present celebre als habitadors de tots sos regnes et terres [...]. Per ço los dits III braços de Cathalunya, qui representen tot

\footnotetext{
${ }^{6}$ Ferran 2001.

${ }^{7}$ Desclot 2009, cap. 139.

${ }^{8}$ Bofarull (ed.) 1866, p. 304.

${ }^{9}$ Ibidem, pp. 303-308.
} 
lo General del dit Principat, constituïts en les dites Corts generals ${ }^{10}$.

En aquest text resulta evident que el "Principat" equival a tot "Catalunya" i posseint un significat tant geogràfic com polític ${ }^{11}$. Una accepció que observem pocs anys després en les Corts de Saragossa de 1381, en les quals es va voler expulsar el noble Hug d'Anglesola: perque es notoriament catalan e domiciliado et heredado en el principado de Cataluenya, et catalan ne otro ninguno strangero del dito regno non podian seyer en la dita Cortes [sic] ${ }^{12}$.

Així, a inicis del segle XV ja trobem plenament consolidada la concepció política que Catalunya és un principat i que el príncep sobirà d'aquest principat és el rei d'Aragó, com a portador de les titulacions comtals de Barcelona, Rosselló i Cerdanya. Per consegüent, en les Corts de 1413, el bisbe de Barcelona féu una suplicació en nom del braç eclesiàstic defensant la preeminència règia davant dels magnats, nobles i cavallers, al·legant que:

No és versemblant que algú no hagués en lo dit principat de Catalunya potestat de fer llei sinó lo comte de Barcinona així com a príncep e senyor del principat de Catalunya, per lo qual foren fets los usatges de Barcinona; lo qual posà llei entre los magnats, comtes, nobles e cavallers ${ }^{13}$.

Amb el pas del temps l'ús de "principat" augmentà tant com a sinònim de "Catalunya" que o bé gairebé sempre acompanya el corònim, o bé, si van per separat, és més emprat que el nom de la terra ${ }^{14}$. Per tant, entre la segona meitat del segle XIV i al llarg del XV el concepte "principat" anà consolidant-se com a nom oficial i popular d'un dels dominis polítics de la península Ibèrica, equivalent, per exemple, als regnes d'Aragó, València, Castella, Navarra o Portugal, per la qual cosa no s'ha de confondre amb una altra mena de principats hispànics com foren els principats dels hereus reials: el d'Astúries, el de Viana i el de Girona.

Exposat això, podem dir ja que l'autèntic problema del concepte rau en determinar el perquè del seu ús per catalogar políticament la Catalunya medieval en comptes del concepte "regne". Pensem que cal esbrinar per quin motiu els comtes sobirans barcelonins i els seus successors reials catalanoa-

\footnotetext{
${ }^{10}$ La citació a Cingolani 2015, p. 241. El parèntesi i el claudàtor són de l'autor.

${ }^{11}$ No sempre que s'emprava aquesta expressió es feia amb aquesta accepció geopolítica, ja que durant els segles XIV i XV el 'principat de Catalunya' també posseïa un significat jurisdiccional en ser sinònim de les terres de jurisdicció reial a Catalunya. Sabaté 1997, pp. 339-340.

${ }^{12}$ La citació a Cingolani 2015, p. 268.

${ }^{13}$ Albert, Gassiot 1928, pp. 112-121. La citació a la p. 117.

${ }^{14}$ Sobrequés 2015, p. 351; Palomo 2018a.
} 
ragonesos no s'intitularen mai rex cathalanorum, conformant un regnum Cathaloniae.

Especialment si posem en relleu que, d'una banda, la categoria de "regne" fou ostentada per molts dels dominis polítics cristians circumveïns, equivalents i molts relacionats amb Catalunya: Aragó, València, Mallorca, Sardenya, Sicília, etc.; i d'altra banda, ja a mitjan del segle XI i, per tant, abans de la consolidació dels comtats catalans com a Catalunya, comptem ja amb la concepció forana d'un ocasional regne barceloní. Aquest figura en el quart llibre dels Miracula Sancti Benedicti compost per un monjo de l'abadia de Fleury, monestir ubicat a la part septentrional del regne de França:

Haec Barcinonensis regni quatuor duces comperientes, Bernardus Bisuldunensium, Guierdus Cerdinensium, Raimundus Barcinonensium, Ermengaudus Urgillensium, in grata planitie Thorani castri, cum quingentis tantum modo armatis, in unum conveniunt.

Aquest regne barcelonès denota la percepció per part del monjo de la unitat del territori català, de la seva profunda autonomia respecte del regne de França, i la primacia de la ciutat de Barcelona en aquest conjunt, malgrat que la presència dels quatre cabdills li impedeix individualitzar-ne un rei ${ }^{15}$.

Finalment, també cal destacar el nou sentit semàntic que, segons exposà el filòleg valencià Antoni Ferrando, adquirí "regne" en el segle XII:

El mot "regne" és un llatinisme manllevat al llatí medieval (no al llatí clàssic, on regnum = "imperi", "comandament"), ja que en llatí medieval era una adaptació o rellatinització d'un mot romanç, re(y)alme. Per tant, "regne" és un cultisme -de semàntica medieval tanmateix - per dir "reialme" (< regimine), mot romanç que s'estengué del nord de França (* reeme > reemme $>$ reamme, al segle XII) a Occitània, on es dissimilà en realme i des d'on, al seu torn passà al nord d'Itàlia i a Catalunya (reyalme, al segle XII). Un "regne" o "reialme" era, doncs, un regimen (= règim) d'ordenament jurídic i polític d'un territori o país, i aquest regimen o reialme tenia les seves lleis, institucions i personalitat pròpia, que constituïa en conjunt un estat de coses públiques (= rei publica [sic]) peculiar. Cada regne medieval de la Corona d'Aragó (a aquests efectes, el títol de "principat" ostentat per Catalunya, a la qual se li donà també qualque vegada el títol de "regne" [...] venia a significar el mateix) fruïa d'un doble regimen: el privatiu i el del sobirà comú de la Corona d'Aragó, d'on [prové] el doble títol de rei de València (en el nostre cas) i rei [de la Corona] d'Aragó ${ }^{16}$.

${ }^{15}$ La citació i la interpretació a Cingolani 2008,p. 171.

${ }^{16}$ Ferrando 1980, pp. 136 i 137. 
Sense entrar a valorar l'etimologia de Ferrando, certament sovinteja entre els segles XIII i XVIII l'ús "regne" per qualificar Catalunya d'una manera genèrica com a entitat política. Per exemple, el podem observar en la retòrica del rei Jaume I quan en la seva crònica no dubtà a deixar escrit: Cathalunya, que es lo meylor Regne d'Espanya, el pus honrat, el pus noble ${ }^{17}$, o en les Constitutions y altres drets de Cathalunya continguessin expressions com: aquests regnes de Cathalunya, Valencia y Aragó ${ }^{18}$.

Amb tot, aquesta utilització de "regne" aplicat a Catalunya era oficiosa, ja que la terra catalana acabà per adquirir de forma oficial la categoria política de "principat". En cercar la raó per la qual no obtingué la dignitat reial, ens trobem amb l'explicació canònica que consisteix a asseverar que Catalunya no pogué ser "regne", perquè aquesta mantenia llaços jurídics de subordinació, tot i que esmorteïts, envers el regne de França.

\section{LA VISIÓ CANÒNICA DE PER QUÈ CATALUNYA NO FOU UN REGNE. LA CONCEPCIÓ DE RAMON D’ABADAL}

L'esmentada interpretació canònica fou establerta pel medievalista vigatà Ramon d'Abadal i de Vinyals (1888-1970) fa més de cinquanta anys ${ }^{19}$. En l'actualitat encara és divulgada i acceptada, ben segurament, perquè fou historiogràficament consagrada amb la celebració commemorativa del Millenari de Catalunya l'any $1988^{20}$.

Aquesta concepció explica que els comtes catalans, que fins a finals del segle IX havien estat oficials al servei dels reis carolingis, van aprofitar la desintegració de l'Imperi franc per, primer, apropiar-se patrimonialment dels diferents comtats i, més tard, per emancipar-se del poder reial i esdevenir els seus comtats independents de fet, però no de dret.

L'exemple més paradigmàtic seria el del comte Borrell II de Barcelona i d'Urgell (947-992), el qual, l'any 985, bo i que feia més d'un segle i mig que les hosts franques no intervenien en les terres de la futura Catalunya, es veié tan indefens enfront de la devastació perpetrada en el comtat i la ciutat de Barcelona per les tropes del cabdill musulmà Almansor, que hagué de demanar socors al sobirà franc. Fou debades, ja que el poder reial ignorà les peticions de Borrell. En aquells anys de 985-987, els reis Lotari I i el seu fill Lluís V, els darrers reis de l'estirp de Carlemany en el regne occidental, es

\footnotetext{
${ }^{17}$ Jaume I d'Aragó, Llibre dels feits, ed. Soldevila, p. 413.

${ }^{18}$ La citació a Lalinde 1997, p. 450.

${ }^{19}$ Abadal 1965, p. 340.

${ }^{20}$ Font, et al. 1989.
} 
trobaven subsumits en una gravíssima crisi que acabà provocant l'extinció de la dinastia carolíngia i l'entronització, l'any 987, del duc Hug de França, més conegut com a Hug Capet.

Poc després, el 988, el nou rei hauria enviat una carta al comte Borrell II oferint-li ajuda militar contra els infidels a canvi de la renovació del seu vassallatge. Tanmateix, el comte no acatà la demanda i d'aquesta manera finà la dominació franca de fet sobre els comtats de Barcelona, Girona, Osona i Urgell. Els comtes de Cerdanya-Besalú-Conflent i el de Rosselló-Empúries també aconseguiren l'apropiació total dels seus comtats sense el trencament explícit del vassallatge.

Ramon d'Abadal insistí que les independències foren de fet però no de dret perquè, segons interpretava, la sobirania jurídica dels reis francesos, tot i quedar inoperant, no desaparegué fins que la independència dels comtats es definí legalment amb el Tractat de Corbeil de 1258. Fins a aquella fita l'erecció oficial dels comtats o de Catalunya a la condició reial no fou possible, especulà el medievalista, per la prudència i l'escrupolositat jurídica dels comtes catalans davant del dret del rei francès. Sobretot dels de Barcelona, que havien ostentat una creixent hegemonia sobre el conjunt territorial català:

Per tal com el rei de França no ha deixat pas d'ésser rei de tot el territori català, qualsevol provatura per a instaurar una jerarquia superior directa sobre la població podria ésser considerada, als ulls dels magnats intermedis, com si fos un acte antijurídic, és a dir, com una usurpació de drets [...] [després de les conquestes de Tortosa i Lleida] fa l'efecte que havia arribat l'hora de proclamar un regne català que comprengués tots els dominis del comte [de Barcelona]. L'escrúpol de juridicitat dels juristes de Ramon Berenguer IV devia aturar-los davant el dret del rei francès ${ }^{21}$.

Després de la signatura del tractat, d'Abadal suposà que no devia interessar Jaume I convertir Catalunya en regne de forma oficial, ja que, d'una banda, posseïa personalment la categoria reial per l'Aragó i, de d'altra, voldria estalviar-se les probables reticències que acompanyarien una proclamació especial de regne per a Catalunya ${ }^{22}$.

Una interpretació canònica que no ha envellit gaire bé, atès que en aprofundir en aquesta, hem advertit que és insostenible arran de diverses qüestions que tractem a continuació.

${ }^{21}$ Abadal 1987,pp. 64 i 67.

${ }^{22}$ Ibidem, pp. 63-67. 


\section{UNA TEORIA BASADA EN INTERPRETACIONS HISTORIOGRÀFIQUES BAIXMEDIEVALS I ALTMODERNES}

Entre els segles XII i XV, els cronistes, juristes i erudits catalanoaragonesos pensaven que el comte Guifré el Pilós obtingué el comtat de Barcelona amb plena independència, o en "franc alou" segons la terminologia baixmedieval. Una idea introduïda en el segle XII amb les Gesta comitum Barchinonensium, la tercera i darrera versió de les quals (finals s. XIII) titulen el capítol tercer "De Guifredo Pilose, qui primo habuit pro alodio comitatum Barchinone" 23 . Tan versemblant i oficial arribà a ser considerat aquest relat de la consecució lliure del comtat per part de Guifré arran d'una donació reial franca, que fou seguit fil per randa pel rei Pere III el Cerimoniós en les seves Cròniques dels reis d'Aragó e comtes de Barcelona (s. XIV) ${ }^{24}$.

Explicà Ramon d'Abadal que el primer autor en trencar amb aquesta visió i distingir una possessió diferent del comtat per part de Guifré, inicialment com a feu, i després alliberar a Catalunya dels invasors, en "franc alou", fou Pere Tomic en la seva obra Histories e conquestes dels Reys de Arago e Comtes de Barcelona (acabada en 1438 i editada en 1495); i que, després d'aquest, fou el cronista i arxiver Pere Miquel Carbonell qui, en les seves Chròniques de Espanya (escrites en el pas del segle XV al XVI) ${ }^{25}$, introduí la idea que Guifré tingué el comtat barceloní en la condició de "feu honrat", essent el primer en negar-li la possessió aloera. En altres paraules, que l'obtingué amb una condició jurídica en què el vassall només havia de jurar fidelitat $\mathrm{i}$ fer homenatge al seu senyor, sense ser forçat a fer servei o pagar cap cens com es feia en els feus comuns. Segons d'Abadal, la tesi de Carbonell fou seguida per molts historiadors catalans posteriors i, entre ells, pel cèlebre cronista barroc Jeroni Pujades ${ }^{26}$.

De fet, i malgrat haver passat desapercebut, el mateix d'Abadal feu avinent que per bastir la seva tesi de la independència de fet i la fi d'aquesta situació politicojurídica amb el tractat de Corbeil, s'havia inspirat en les interpretacions de Jeroni Pujades sobre com el comtat de Barcelona se separà del domini franc en el període medieval ${ }^{27}$.

\footnotetext{
${ }^{23}$ Gestes, ed. Cingolani, p. 64. Segons explica Stefano M. Cingolani, la primera vegada que s'escrigué sobre aquest episodi històric fou en la primera redacció de les Gesta, redactada entre 1180 i 1184 . Cingolani 2012.

${ }^{24}$ Pere III d'Aragó, Crònica General, ed. Soberanas, p. 79.

${ }^{25}$ Carbonell, Cròniques d'Espanya, ed. Alcoberro.

${ }^{26}$ Abadal 1997, p. 53.

${ }^{27}$ Ibidem, pp. 49-61 i 140.
} 
Certament, Pujades tractà aquestes qüestions en els capítols 31 i 32 del llibre novè de la segona part de la seva Crónica universal de Cataluña, escrita entre 1620 i 1635 aproximadament. En ells l'autor exposà que considerava errònia la interpretació que sostenia que el comte Guifré el Pilós aconseguí la lliure propietat del comtat de Barcelona i principat de Catalunya de mans de l'emperador Carles II, nét de Carlemany, com a recompensa per reconquerir als musulmans el territori barceloní sense ajuda del seu senyor. Pujades mantenia que, si bé l'emperador havia recompensat el comte amb la possessió del comtat barceloní - plenament identificat com a principat català, puix que pels historiadors de l'època eren dues categories polítiques vinculades des dels temps altmedievals-, no li entregà lliure (o en alou), sinó en forma de feu honrat o franc ${ }^{28}$.

No obstant això, Pujades considerava que aquesta condició de vassallatge honrat ja hauria desaparegut el segle XI, puix que el comte Ramon Berenguer I ja era el senyor suprem i propietari lliure del comtat de Barcelona, com demostra el fet que creà lleis comunes per a tots els seus súbdits (els Usatges de Barcelona ${ }^{29}$. Per aquest autor, finalment, el domini aloer de Catalunya per part dels comtes de Barcelona quedaria totalment confirmat amb el tractat de Corbeil. Pujades resumeix l'explicació de la següent manera:

Así pues, el conde Wifredo de esta vez no quedó alodario en el
condado sino con feudo de dignidad que llaman franco ú honrado,
el cual despues se acabó en ocasion de las grandes turbaciones
que hubo en Francia ó por prescripción, dejación y desamparo de
socorrer aquellos reyes á nuestros condes; y últimamente por la
relajación y renunciación del santo rey Luis concertándose con
nuestro rey D. Jaime primero; el cual con toda seguridad quedó
absoluto señor alodial y supremo en todo este principado, sin re-
conocer á otro en lo temporal, sí solamente á nuestro Dios señor
común del universo ${ }^{30}$.

D'aquesta manera, Pujades se serveix del tractat de Corbeil entre Lluís IX de França i Jaume I d'Aragó, com a justificant darrer de la seva interpretació. No fou ni el primer ni l'únic que ho féu, perquè el predit tractat ha estat instrumentalitzat per cronistes i historiadors, des de finals del segle $\mathrm{XV}$ en endavant, per tal de fer-lo servir d'aval justificador de les seves teories sobre història política de la Catalunya medieval, les quals habitualment contradeien la visió baixmedieval imposada per les Gesta.

\footnotetext{
${ }^{28}$ Pujades 1829-1832, vol. 6, llibre. 9, cap. 32, pp. 312-314.

${ }^{29}$ Ibidem, pp. 315-316.

${ }^{30}$ Ibidem, p. 318.
} 
Exposat això, cal dir que la interpretació d'Abadal presenta alguns errors, com per exemple, l'asseveració que Pere Miquel Carbonell fou el primer en negar la possessió alodial de Barcelona/Catalunya per part del comte Guifré, perquè la calendació dels documents a nom del rei franc li feia suposar [a Carbonell] que no existia tal independència ${ }^{31}$, i més endavant afegeix: Carbonell fou qui, a últims del segle $X V$, assenyalà aquest fet [la calendació segons el regnat franc] com a expressiu de la continuació de la sobirania franca després de Guifred el Pilós ${ }^{32}$.

Les cròniques de Carbonell contradiuen aquesta darrera afirmació de Ramon d'Abadal ja que, en primer lloc, si bé Carbonell sostingué que el comtat de Barcelona li fou infeudat a Guifré com a feu honrat, després, quan aquest comte foragità los moros, posseí:

tot lo seu comtat segurament a tot la sua voluntat, tenint e posseint aquell franch e quiti de tota subjecció. A la qual en lo temps abans era obligat per lo rey de França; qui aprés com davall és conegut, lo enaloà e renuncià tot son dret que hi tenia aquest comte Guifré33.

I, en segon lloc, bo i que Carbonell certament indica que el costum de calendar els documents era perillosa per als catalans perquè podria ser una indicació que el rei de França continuava tenint algun domini sobre Catalunya, tanmateix, per l'arxiver aquesta situació de domini francès havia expirat en temps de Guifré el Pilós, fet que quedà totalment confirmat amb el tractat de Corbeil. D'aquesta manera, escrigué que l'any 1180:

fonch ordenat que d'aquí avant los notaris en les cartes no metessen lo chalendari dels reys de França, lo qual acostumaven a metre, ans haguessin a posar en aquelles l'any de la incarnació de Jesuchrist, com no fos cosa pertinent, ans molt perjudicial, als comtes de Barcelona, y encara als catalans, que ens les cartes se hagués a fer menció del rey de França, que en aquell temps no tenia ningun dret en lo comtat de Barcelona ne en les altres terres del principat de Catalunya; com dos reys de França ho havien lexat, e aprés, a qualsevol dret li pertangués en aquell ni en aquells, aquell sanct rey de França apellat Loys novus transigit, renunciat e diffinit, com apar per carta pública de transacció, eccessió, diffinició, et renunciació per acò feta e fermada per lo predit rey Loys al gloriós e gran conquistador rey d'Aragó apellat Jaume primer ${ }^{34}$.

\footnotetext{
${ }^{31}$ Abadal 1997, p. 53.

${ }^{32}$ Ibidem, p. 141.

${ }^{33}$ Carbonell, Cròniques d'Espanya, ed. Alcoberro, vol. 2, p. 17.

${ }^{34}$ Ibidem, p. 40.
} 
Certament, Carbonell introduí el concepte de "feu honrat", advertí sobre les datacions franques i, potser, fou el primer autor a servir-se del tractat de Corbeil com a prova definitiva de la renúncia per part del rei de França a qualsevol dret que pogués tenir sobre part de Catalunya. No obstant això, l'arxiver, com tota la tradició que el precedia des de finals del segle XII, va considerar Guifré I com a comte aloer i explicà que en 1180, quan s'ordena que no es dati la documentació segons els regnats francesos, els reis de França no tenien cap dret sobre Catalunya. Per tant, va ser una altra persona la primera en negar el domini alodial del Pilós i dels seus successors.

Les Cròniques de Pere Miquel Carbonell no foren editades fins a l'any 1547 , tenint a partir d'aleshores una difusió significativa. Un dels seus lectors fou el cronista valencià Pere Antoni Beuter. Aquest, en la seva Segunda parte de la Coronica general de España (1551), a més de citar Carbonell, s'inspira en part en ell per parlar sobre la qüestió de Catalunya en l'àmbit de les relacions dels reis de França amb els comtes de Barcelona. En una nota marginal escrigué:

Tuvieron por costumbre los notarios Cathalanes, de poner en sus Kalendarios de sus autos y cartas, el rey que en Francia reynava, y el año de su reyno, hasta que el rey Loys noveno deste nombre y llamado el santo, lo reunncio al rey don Iayme que gano Valencia, y fue esta renunciacion año del señor .1250. qnto idus Maii. en Claramont de Alvernia, no muy lexos de Monpeller. Esta la carta en el archio de Barcelona: en el armario de los negocios de Cathaluña, en la letra A. Haziase aquello primero por reconoscimiento de señorio que los reyes de Francia solian tener en Cathaluña ${ }^{35}$.

En aquesta nota no estigué gaire encertat Beuter, ja que els regnats del rei franc es deixaren d'utilitzar en la documentació catalana des de 1180,i no pas des de 1258, l'any en què té lloc el tractat de Corbeil, ni de 1250, data que el cronista valencià escrigué erròniament, atès que en la mateixa obra ens ofereix l'any correcte del tractat, com veurem. Sigui com sigui, Beuter anotà: don jofre Velloso [...] fue tercero conde de Barcelona, en franco alodio ${ }^{36}$, però quan profunditza en el tema, diu que l'emperador franc prometé al comte Guifré:

que si podía defender la tierra de Cathaluña que le quedaba y cobrar lo que havia perdido, o qualquier otra tierra de nuevo, que el condado de Barcelona, y principado de Cathaluña fuessen suyos propiamente para el y los suyos, con feudo que por el le recon-

${ }^{35}$ Beuter, Coronica general, cap. 12, f. 32v. En cursiva les abreviatures en totes les citacions.

${ }^{36}$ Ibidem . 
osciesse como superior, y pudiessen a el recurrir en causas de appellacion. Esta donación, y enfeudacion fue hecha año del Señor ochocientos y ochenta quatro, y de entonces se tomo por costumbre de poner en las cartas el año del Rey que en Fracia reynava. Estan las cartas de la donación en el archio de Barcelona. Y antes desta donación dava el Rey de Francia el condado de Barcelona a quien bien le parescia, y al tiempo que se le antojava. [...] Dizen los Cathalanes que este conde ovo el condado en franco alodio libre de toda sojecion del Rey de Francia, pero yo hallo lo contrario, porque Lotario que fue muchos años después dio el privilegio que arriba truximos al Abbad de sant Cucufato. Y adelante mostraremos como esta general exempcion y libertad otorgo el Rey Loys el santo al Rey don Iayme nuestro ${ }^{37}$.

També cità Carbonell quan torna a tractar sobre el mesmo .1258. a tres de Mayo, quan el rei de França:

renuncio y transporto y diffinio todos los juros, derechos y acciones que se podian por su parte pretender en dicha tierra de Cathaluña, y dende entonces no se pusieron en los calendarios de los notarios, los años de los reyes de Francia, como se halla este aucto en el Archio de Barcelona, segun dize el coronista Cathalan Miguel Carbonell, hablando del Rey don Iayme ${ }^{38}$.

Així, fou Beuter i no Carbonell qui negà l'al·loditat a Guifré el Pilós . Per tant, el cronista Jeroni Pujades s'inspirà, en part, en Beuter, quan tractà aquestes qüestions que ens ocupen.

Ja hem exposat l'opinió de Pujades anteriorment, però cal explicar com arribà a la seva teoria sobre el tractat de Corbeil.

Segons Pujades, la situació del feu honrat entre Guifré I de Barcelona i Jaume I d'Aragó quedaria totalment confirmada per l'existència del tractat de Corbeil, idea que el cronista afirmà obtenir de la crònica de Beuter i confirmar amb la documentació de l'Arxiu Reial de Barcelona ${ }^{39}$. D'aquesta manera arribà Pujades a la conclusió que Guifré I i els seus successors no tingueren Barcelona-Catalunya en alou, almenys de dret, fins al tractat de Corbeil, i si bé Ramon Berenguer I ja era de facto senyor alodial de Catalunya, fou Jaume I qui quedà amb tota seguretat legal com a absolut senyor alodial i suprem en tot el Principat.

Hem seguit aquesta evolució historiogràfica fins a arribar al punt intermedi que ens plantejà Jeroni Pujades: ni Guifré aloer (tradició medie-

${ }^{37}$ Ibidem, cap. 13, f. 34v.

${ }^{38}$ Beuter, Coronica general, cap. 50, f. 143r.

${ }^{39}$ Pujades 1829-1832, vol. 6, llibre 9, caps. 31-32, pp. 309-319. 
val i Carbonell) ni alt senyoriu del rei de França fins a Jaume I (Beuter). I ho hem fet perquè Ramon d'Abadal es guià per la lògica de Pujades, del qual deia que havia encarrilat per la bona via la qüestió històrica de la sobirania dels nostres comtes.

En conseqüència, la concepció d'Abadal pateix un greu problema de mètode, ja que ofereix una visió errònia de Carbonell i descontextualitzada tant de Pujades com del mateix Carbonell, considerant-los simplement com a recercadors objectius de l'origen històric de Catalunya, sense valorar les motivacions conjunturals que els portaren a sostenir els seus posicionaments historiogràfics.

Els darrers segles medievals i els altmoderns són una època en què les interpretacions històriques podien tenir repercussions de primer ordre en la vida política, institucional i jurídica en qualsevol comunitat política d'Occident. Per aquest motiu, es produïa una esparverant utilització del discurs històric com a justificació política per part dels poders establerts (Corona, Església, aristòcrates, parlaments, governs municipals, etc.), que ben sovint actuaren de mecenes, promotors i censors de les obres.

Per exemple, a la Catalunya del segle XVI i, sobretot, d'inicis del segle XVII, on l'alta jurisdicció basculava entre dos grans pols de poder (la Corona i les institucions dites de la terra: els tres Braços en Corts, la Diputació del General de Catalunya i el Consell de Cent de Barcelona, principalment), existí un fervorós debat entre historiadors -generalment, juristes i eclesiàstics- sobre l'origen medieval de Catalunya a fi de justificar, en clau més regalista o més constitucionalista, el tipus de relació política que havien de mantenir els monarques hispànics de la Casa d'Àustria amb els seus súbdits catalans.

Una de les qüestions principals a dirimir era la de l'origen de la sobirania del comte de Barcelona i, en relació amb aquesta, els més proclius als posicionaments regalistes defensaven que el comte rebé la sobirania del rei francès de fet però no de dret (feu franc o honrat), mentre que els contraris mantenien que la rebé de dret i de fet (franc alou). D'aquests posicionaments participà plenament, com hem vist, Jeroni Pujades, qui a més destacà per la seva marcada evolució ideològica amb el pas dels anys, ja que si bé a inicis de la dècada de 1620 era un cèlebre autor reialista, en el començament de la següent era un apologeta dels posicionaments defensats pels autors proclius a la terra ${ }^{40}$.

${ }^{40}$ Villanueva 1994. 


\section{CoMTATS DELS SEGLES IX-XIII A MODE D’ESTATS DELS SEGLES XIX I XX}

Un altre problema de mètode, vist des de l'actualitat, consisteix en el fet que Ramon d'Abadal no només feu una adaptació dels posicionaments de Pujades al nivell de coneixements propi de mitjan segle XX -substitució de Guifré I i Carles II per Borrell II i Hug I, substitució de la conquesta sarraïna de Barcelona en el segle IX per la ràtzia d'Almansor de 985 , etc.-, sinó que aquesta adaptació es veu immersa en els paràmetres del món geopolític dels segles XIX i XX, quelcom, d'altra banda, propi de la historiografia de la seva època. Per exemple, en la temàtica que estem tractant continuaven la mateixa discussió historiogràfica que els autors d'Antic Règim, però ara amb un vocabulari més modern: en comptes de "feus" o "alous", se'ns parla d'una "proclamació d'independència" i del reconeixement francès d'aquesta ${ }^{41}$.

Tanmateix, tractar d'independències dels comtats en relació amb el regne de França; cercar una proclamació d'independència en el suposat trencament entre el rei Hug i el comte Borrell; concebre els drets reivindicats pels reis de França sobre els comtats catalans com una alta sobirania dels Capets mantinguda durant dues centúries i mitja; defensar que l'esmentada alta sobirania s'extingiria amb el Tractat de Corbeil; afirmar que el tractat reconeixia de dret les predites independències comtals i utilitzar tot això com a explicació al fet que els comtes de Barcelona dels segles XI-XIII no prengueren el títol de reis de Catalunya, és retrotreure anacrònicament la lògica dels estats-nació contemporanis a aquelles llunyanes centúries.

En el món de la feudalitat naixent, la llei i la legitimitat política s'adaptaven contínuament als nous poders emergents, en la mesura que senyors i llinatges tingueren força per imposar-se de manera efectiva sobre un territori i la població d'aquest, com fou el cas dels diferents comtes i dinasties comtals en relació als comtats que acabarien per conformar Catalunya. En aquest sentit, el procés d'emancipació comtal respecte a la reialesa franca fou una gradual i quotidiana assumpció del poder entre els segles IX i XI.

Per molt que es busqui, difícilment es podrà trobar mai una declaració comtal d'independència, que seria allò propi de societats més modernes, ni que sigui en forma d'un trencament explícit de vassallatge com el que se li ha estat atribuint al comte Borrell II.

Per tant, l'objectiu del tractat de 1258 no era pas legalitzar les illegals independències dels comtes catalans produïdes més de dos-cents cinquanta anys enrere, sinó, com veurem, d'una aliança entre dos reis del

${ }^{41}$ Abadal 1997, pp. 54-61. 
segle XIII, materialitzada a través de la renúncia mútua a drets, per evitar-se problemes geopolítics l'un amb l'altre.

Consegüentment, no sembla gens realista concebre que els comtes de Barcelona i, més tard, els reis d'Aragó dels segles XII i XIII no s'atribuïssin el títol de "rei de Barcelona" o de "rei de Catalunya" a causa de l'escrupolós respecte a la potestat d'una antiquíssima dinastia extinta el 987, potestat que, a més, els sobirans catalanoaragonesos d'aquestes centúries consideraven que era seva des dels temps de Guifré el Pilós, com es veu reflectit en cròniques com les Gesta Comitum Barchinonensium o els documents de propietat recollits en el Liber Feudorum maior (finals del segle XII ${ }^{42}$.

En definitiva, la modernització que dugué a terme Ramon d'Abadal de la concepció de Pujades és una explicació senzilla (trencament de la relació de vassallatge en el segle $\mathrm{X}$ i reconeixement de les independències comtals en el XIII) al fet que els comtes de Barcelona no prengueren el títol de reis de Catalunya, basada en pressupòsits fonamentats en teories historiogràfiques de l'època moderna, els quals, a més no han estat confirmats per l'avenç de les investigacions. Si repassem, per exemple, allò que sabem d'alguns moments clau de les relacions francobarcelonines entre els temps del comte Borrell II i del rei Alfons I, veiem que les coses no són pas tan senzilles com sosté l'explicació canònica d'Abadal.

\section{FETS CLAU DE LES RELACIONS FRANCOBARCELONINES DELS SEGLES X-XII}

Per començar, cal posar en relleu que no tenim documentació directa sobre la suposada demanda d'ajuda del comte Borrell al rei Lotari. L'única notícia que existeix és un intercanvi de cartes entre el monjo cortesà Gerbert (futur papa Silvestre II) i l'abat Guerau d'Orlach (futur sant). Gerbert diu a l'abat que no creu que el rei Lluís V socorri el comte Borrell, per la qual cosa els historiadors han deduït que Borrell degué demanar ajuda a la cort carolíngia. Per tant, no sabem en quins termes demanà el comte el suposat auxili al rei franc i si li prometé fidelitat o no. I això no és tot. També cal tenir en compte que, si bé s'ha conservat la carta del rei Hug dirigida al comte Borrell, en què se supeditava l'auxili militar al jurament de fidelitat, explica Michel Zimmermann que, segurament, aquesta ni tan sols fou expedida ${ }^{43}$.

\footnotetext{
${ }^{42}$ Cingolani 2010, pp. 219-252. Segons aquest autor, la coherència ideològica d'ambdues reforça, encara més, la vinculació de les Gesta amb la voluntat i supervisió del rei Alfons I. Cingolani 2012, pp. 14-24.

${ }^{43}$ Zimmermann 1991.
} 
Així, la versió que concep l'emancipació dels comtats catalans com el trencament d'un lligam feudovassallàtic entre Hug i Borrell no es correspondria gaire amb uns fets històrics que són gairebé impossibles de conèixer per l'escassetat de documentació.

A més, resulta imprudent parlar de vassallatge en les relacions de fidelitat entre grans senyors en aquest moment ja que, ben possiblement, el vassallatge feudal clàssic -usdefruit d'un feu per al vassall a canvi d'homenatge, auxili i consell per al senyor- en què la historiografia tradicional ha enquadrat tradicionalment la relació entre els comtes de la pre-Catalunya i els reis carolingis, és molt més propi dels segles XI, XII i posteriors, que no pas dels segles IX i X ${ }^{44}$.

Llavors, un cop vista la manca de documentació per copsar correctament els fets dels anys 985-988, per tal d'esclarir quin tipus de vincle existí entre els comtes de Barcelona i els reis de França, és menester resseguir-ne alguns moments clau de la relació en els dos segles posteriors. Amb tot, les fonts continuen sense ser abundants.

Per exemple, l'abat benedictí de Saint Pierre le Vif de Sens (Borgonya) informa que, a inicis de l'any 1109, el comte Ramon Berenguer III envià una ambaixada al rei Lluís VI de França per demanar-li ajuda per aturar la pressió dels musulmans almoràvits, els quals havien subjugat les taifes andalusines, conquerit la València del Cid i derrotat les forces del rei Alfons VI de Lleó i Castella en la batalla d'Uclés l'any 1108. Tot i que Lluís VI, a fi de poder enfrontar el perill islàmic, es comprometé a fer treves amb els seus vassalls enemics: el rei Enric I d'Anglaterra -que també era duc de Normandia-, el duc de Borgonya, el duc d'Aquitània i comte de Poitiers i altres grans senyors que es negaven a sotmetre's al rei francès. Tot i això, la seva ajuda va quedar en no-res. Com que en aquesta ocasió tampoc disposem de la documentació tramesa entre el comte barceloní i el rei, mai sabrem ben bé com succeïren els fets.

De tota manera, si ens hem de guiar pel testimoni de l'abat -l'únic document que coneixem sobre el fet- interpretem que la petició d'ajuda del comte Ramon Berenguer al rei francès segurament s'ha de considerar més com una petició d'auxili d'un sobirà cristià a un altre que està ubicat a la seva rereguarda, que no pas com la demanada de protecció d'un vassall al seu senyor. Almenys, de l'escrit abacial no es destria pas que el comte de Barcelona estigués sotmès al rei de França, ja que en el document el prelat indica explícitament que els ducs de Normandia i Borgonya, així com altres magnats que estaven sota el rei francès, li denegaven l'homenatge vassallàtic que li

${ }^{44}$ Sabaté 2010, p. 173. 
devien, sense incloure el comte barceloní entre ells, ni utilitzant-lo, tampoc, com a obedient contraexemple amb relació als rebels ${ }^{45}$.

Un altre cas que hem d'analitzar és el de la visita que realitzà l'any 1154 el rei Lluís VII de França als regnes i comtats d'Espanya en pelegrinatge a Santiago de Compostel·la. Durant el seu periple es reuní amb Alfons VII de Lleó i Castella, amb Garcia VI de Pamplona i amb Ramon Berenguer IV de Barcelona i Aragó. Tal com indica Josep-David Garrido Valls, darrer biògraf de Ramon Berenguer IV, no hi ha cap font on s'esmenti una vinculació feudal que sotmeti el comte de Barcelona i príncep d'Aragó al rei francès ${ }^{46}$.

Sigui com sigui, l'hipotètic sotmetiment del comte de Barcelona al rei francès té encara menys sentit en temps d'Alfons I el Cast, rei d'Aragó i comte de Barcelona, quan a Catalunya fins i tot s'anul-là el sistema de datació de documents segons els regnats francesos (any 1180). Nogensmenys, tant d'Abadal com José Antonio Maravall varen considerar que no s'havia de sobredimensionar aquest fet, perquè al parer d'aquests experts, des de finals del segle $\mathrm{X}$, el mètode de datació segons els regnats francs havia esdevingut un simple procediment cronològic que s'emprava per tradició i no com a reflex de la situació política ${ }^{47}$.

Vist això, hem de parar atenció a la interpretació del tractat de Corbeil com a reconeixement legal de les independències comtals i de la conseqüència que deriva de tot plegat: Catalunya no aconseguí la categoria de regne perquè els comtes barcelonins dels segles X-XIII respectaven l'alta sobirania del rei francès.

\section{EL TRACTAT DE CORBEIL}

Pel que fa a Catalunya, aquest tractat de 1258 fa constar que el rei de França cedí i trameté totalment en el rei d'Aragó qualsevol dret i possessió que gairebé tenia o havia pogut tenir o deia tenir, tant en els dominis o senyories com en els feus i qualssevol altres, en la majoria comtats catalans:

dominus rex Francie, pro se et heredibus et successoribus suis, predicto domino regi Aragonum, et heredibus ac successoribus suis inperpetuum, et ab ipso et antecessoribus suis causam habentibus, et nobis procuratoribus predictis pro ipso domino rege Aragonum et vice ipsius, deffinivit, quittavit, cessit, et omnino remisit quicquid juris et possessionis vel quasi habeat, vel habere poterat, seu eciam dicebat se habere, tam in domaniis sive dominicatu-

${ }^{45}$ Benito 2009, pp. 32-33.

${ }^{46}$ Garrido 2014, pp. 255-256.

${ }^{47}$ Maravall 1954; Abadal 1965, p. 339. 
ris, quam feodis et aliis quibuscumque, in predictis comitatibus Barchinone et Urgelli, Bisulduni, Rossilionis, Empurdani, Ceritanie, Confluentis, Gerundensi et Eusonensi ${ }^{48}$.

El rei d'Aragó, per la seva part, cedí al rei francès els seus drets sobre Carcassona, Narbona, Millau, Gavaldà i Tolosa, entre altres territoris (11 de maig de 1258). La cessió dels drets de Jaume I sobre la Provença es feren a través de la persona de la seva cosina, Margarida de Provença, reina consort de França (17 de juliol de 1258).

En aquest cas, la reivindicació de drets que començà a fer Lluís IX de França sobre la majoria de comtats de Catalunya a partir de 1254, presentantse com a successor dels carolingis en el regne occidental, li podia servir com a excusa per declarar la guerra al rei d'Aragó; per reclamar els mateixos territoris en cas que el llinatge masculí dels reis d'Aragó s'extingís; per exigir al rei catalanoaragonès una submissió vassallàtica; o per cedir-los al rei d'Aragó a canvi d'uns altres drets més útils per a ell, cosa que finalment succeí.

Tot i que desconeixem quin rei proposà a l'altre fer el tractat de Corbeil, per Ferran Soldevila ${ }^{49}$ aquest pacte fou un triomf del rei Lluís qui, a canvi de renunciar a uns hipotètics, obsolets i improvisats drets del segle IX sobre la major part dels comtats catalans, rebé la renúncia del rei d'Aragó a uns drets històrics acumulats per l'estirp barcelonina en els segles XI, XII i XIII -és a dir, cronològicament, molt més vigents- sobre una multitud de dominis ubicats als territoris de Tolosa, Llenguadoc i Provença que, en aquell 1258, ja dominaven el rei francès o els seus germans, com veurem. Així, s'intentaria assegurar un plàcid control sobre l'espai que en l'actualitat anomenem Occitània, una terra per la qual, durant la primera meitat del segle XIII, la casa reial de França havia hagut d'enfrontar-se amb els reis d'Aragó, els d'Anglaterra i amb els comtes de Tolosa, entre altres grans senyors.

Amb tot, en opinió de Stefano Maria Cingolani, el rei d'Aragó no en sortí pas malparat.

En primer lloc, cal tenir en compte la dolenta perspectiva per al domini catalanoaragonès que presentaven les regions de Tolosa, Llenguadoc $\mathrm{i}$ Provença després de la derrota i mort del pare de Jaume I, el rei Pere I el Catòlic, en la batalla de Muret (1213), la qual permeté als reis francesos, amb la promoció i protecció del Papat, estendre la seva influència en la zona i, sobretot, consolidar-la, després que els germans del rei francès (el comte d'Anjou i Maine i el comte de Poitiers), esdevinguessin per via matrimonial comte de Provença (1246) i comte de Tolosa (1249), respectivament.

${ }^{48}$ Laborde (ed.) 1873, tom 3, pp. 405-408. Citació a la p. 406.

${ }^{49}$ Soldevila 1962, vol. 1, pp. 295-304. 
En segon lloc, per si mateixos, els territoris occitans eren un vesper poc rendible. El llinatge del rei Jaume hi havia invertit molts recursos i vides amb resultats ben efímers, ja que la dificultat per imposar ordre i autoritat damunt la noblesa occitana era proverbial, raó per la qual cap príncep havia aconseguit crear un domini feudal fort i estable ${ }^{50}$.

A part, també hi havia el tema de Montpeller, que no figura en el tractat, però que resulta un factor clau per entendre'l millor. La rica ciutat tenia seriosos problemes des de $1252 \mathrm{amb}$ Jaume I per l'intent del rei d'apropiar-se de part de la tributació municipal. Això impel·lí la burgesia montpellerina a cercar l'ajuda del veí vescomte de Narbona i del bisbe de Magalona -senyor pel qual el rei d'Aragó tenia Montpeller en feu-, el qual es va fer vassall del rei de França i declarà que el rei Jaume I d'Aragó posseiria Montpeller en règim de subinfeudació, fet que podria haver conduït a la indesitjable situació de trobar-se Jaume com vassall del rei de França. A parer de José Luis Villacañas, fins i tot hi havia la possibilitat que el rei d'Aragó perdés la legitimitat per reclamar el domini sobre Montpeller, per l'incompliment dels pactes vassallàtics amb la ciutat i l'aproximació montpellerina a França ${ }^{51}$.

Un cop signat el tractat de Corbeil amb el rei Lluís, s'anul·là el perill francès, i Jaume féu acte de presència a Montpeller a finals de 1258. Llavors, amb una amnistia i una ratificació de l'autogovern montpellerí, el rei recuperà la fidelitat de la ciutat que el veié néixer ${ }^{52}$.

Així, doncs, podem concloure que, gràcies al tractat de Corbeil, Jaume I renunciava a uns drets occitans que difícilment podria fer efectius, alhora que liquidava, en principi, la possibilitat de qualsevol reivindicació futura dels expansionistes reis de França sobre els seus dominis.

Posats a conjecturar, la reclamació francesa sobre els comtats catalans, més que una guerra que comportés l'entrega de mitja Catalunya a Lluís IX, podria haver suposat forçar l'establiment d'una relació de subordinació feudovassallàtica dels reis d'Aragó envers els de França per tal d'evitar el conflicte bèl·lic. No s'ha de perdre de vista ni la situació de Montpeller, arran de l'actuació del bisbe de Magalona, ni el fet que, pocs dies després de l'establiment del tractat que ens ocupa, se signà el tractat de París (28 de maig) pel qual el rei d'Anglaterra es reconeixia vassall del de França per territoris occitans d'Aquitània i Gascunya. Per tant, el tractat de Corbeil allunyava el sobirà catalanoaragonès de problemes amb tres prínceps (el rei de França, el comte d'Anjou-Maine-Provença i el comte de Poitiers-Tolosa) de la família reial més

\footnotetext{
${ }^{50}$ Cingolani 2007, pp. 281-289.

${ }^{51}$ Villacañas 2003, p. 478.

${ }^{52}$ Ibidem, pp. 477-484; Belenguer 2007, pp. 251-259.
} 
poderosa de la cristiandat llatina, uns enemics extremadament perillosos i, això sense comptar el seu aliat pontifici. Prou maldecaps tenia ja el rei d'Aragó en aquells temps per pacificar les revoltes nobiliàries catalanoaragoneses, fer front als aixecaments dels sarraïns valencians i impedir l'hegemonia, en l'àmbit ibèric, del seu gendre, Alfons X de Castella i Lleó.

Per tant, un cop vist allò que ens indica l'estat de coneixement actual sobre les relacions francobarcelonines i sobre les motivacions del tractat de Corbeil, constatem que ni els reis francesos tenien cap sobirania vassallàtica sobre Catalunya -respectada escrupolosament pels comtes de Barcelona i reis d'Aragó dels segles XI, XII i XIII i la qual provocà que el territori no assolís la condició de "regne"-, ni el tractat de 1258 respon a la necessitat catalanoaragonesa de reconeixement francès a les independències comtals de finals del segle $\mathrm{X}$.

\section{HIPÒTESIS SOBRE LA MANCA D’UN TÍTOL REGI PER A CATALUNYA}

Llavors, enfront de l'explicació habitual de l'alta sobirania reial francesa, que acabem de declinar, pensem que la manca del títol reial català ha de respondre a altres motius.

Primerament, si tractem el període anterior a la consecució de la sobirania sobre l'Aragó per part del comte de Barcelona (1137), cal obrir la perspectiva a l'àmbit hispà $i$ considerar per quina raó els sobirans asturlleonesos i pamplonesos, i més tard els seus homòlegs castellans, aragonesos i portuguesos, es legitimaren amb el títol de rex, mentre que els comtes catalans -i pensem sobretot en el de Barcelona- no ho feren.

En els regnes i comtats cristians de la península Ibèrica posteriors a la consolidació d'Al-Andalus, més enllà dels principis legitimadors de l'administració de l'alta justícia i de la promulgació del dret, de la fundació i protecció d'esglésies i de la voluntat divinal, o sigui, el de ser gratia Dei rei o comte (recurs que el comtes catalans empren ja des del la segona meitat del segle X com a recolzament fonamental en la seva ascensió a la sobirania dels seus comtats ${ }^{53}$ ), existia una tradició de tipus patrimonial que convenia que els reis i comtes només estaven legitimats per ser-ho gràcies a uns drets dinàstics i familiars sobre les dignitats reial 0 comtal $^{54}$.

Per aquest motiu els cognoms de reis i comtes sobirans foren patronímics fins al segle XII, i en les escriptures reials asturlleoneses, reials plamploneses i comtals catalanes, per exemple, el nom del rei o del comte anava ben

${ }^{53}$ Cingolani 2008; Salrach 2011, pp. 30-32.

${ }^{54}$ Cingolani 2008, p. 138. 
sovint seguit del nom del pare, habitualment l'antecessor familiar en el càrrec, tot i que, eventualment, els sobirans foren successors dels seus germans, oncles, cosins o sogres $i$, en alguns regnes de les mares.

La legitimitat familiar ens permet formular la hipòtesi que en el segle XI els reis dels aragonesos passaren de la dignitat comtal a la reial, com a descendents directes - malgrat que per línia bastarda- del rei pamplonès, i que el comte dels castellans esdevingué rei de Castella perquè era fill del rei pamplonès. Tot i que, en aquest darrer cas, cal tenir en compte que, primerament, mitjançant les vies matrimonial i bèlllica, el comte castellà esdevingué rei de Lleó i, llavors, canvià la categoria política de Castella.

En allò que respecta al primer rei de Portugal, si bé el comte Alfons Henriques era net per via materna i borda del rei de Lleó, la seva consolidació com a rei portuguès sembla dependre més de poders externs com el rei $\mathrm{Al}$ fons VII de Lleó i de Castella, en la seva condició d'emperador hispà, i el papa de Roma, els quals el reconegueren com a rei després que esdevingués, respectivament, el seu vassall ${ }^{55}$.

Pel que fa als comtes del nord-est peninsular del segle X i XI -la majoria descendents directes de Guifré el Pilós, comte de Barcelona, de Girona, d'Osona, d'Urgell, de Cerdanya i de Conflent- cal dir que, si bé mai deixaren d'emprar títol comtal que havien heretat dels seus progenitors i germans, aquests comtes no només s'arrogaren l'autoritat, la majestat i la potestat dels reis francs ${ }^{56}$, sinó que, a més, alguns d'ells adduïren que tal cosa havia estat volguda per Crist o Déu, per a la defensa dels cristians contra els musulmans ${ }^{57}$ $\mathrm{o}$, fins i tot, referendada pel poder imperial carolingi ${ }^{58}$. Una invenció, aquesta darrera, de caràcter historiogràtic que fou novament formulada durant la segona meitat del segle XII en benefici del comte barceloní i rei aragonès, a través de la primera crònica -en el sentit estricte- de Catalunya: la versió primitiva de les Gesta. Com ja hem vist, les Gesta conceben que el comte Guifré rebé del rei franc el comtat del Barcelona amb totes les prerrogatives del poder reial ${ }^{59}$, cosa que el legitimà a ell i també als seus descendents, com a sobirans d'un comtat de Barcelona que, a cavall dels segles XII i XIV, quedà equiparat a tot Catalunya ${ }^{60}$.

\footnotetext{
${ }^{55}$ Narbona 2015.

${ }^{56}$ Vegeu-ne diverses mostres de la primera meitat del segle XI, així com la seva interpretació que subscrivim a Cingolani 2008, pp. 168-172. Amb tot, en una ocasió Berenguer Ramon I de Bracelona s'anomena ell mateix "comes et regis de Barchinona", i Ermengol IV d'Urgell parla dels seus dominis com a "regno meo". Cingolani 2008, pp. 169-170.

${ }^{57}$ Ibidem, p. 145.

${ }^{58}$ Salrach 2011.

${ }^{59}$ Cingolani 2008, p. 173 .

${ }^{60}$ Sabaté 1997, pp. 333-335; Cingolani 2015, pp. 156-158 i 168-170.
} 
En parlar sobre les Gesta estem tractant sobre la legitimació de caràcter històric del poder sobirà. En la Cristiandat ibèrica dels segles $\mathrm{X}-\mathrm{XV}$, la principal legitimació fou el neogoticisme o entroncament i continuïtat de la classe dirigent cristiana septentrional amb el regne visigot anterior a la invasió musulmana. Així, des de mitjan segle IX en endavant, els cronistes al servei dels reis d'Astúries, Lleó i, més subsidiàriament els de Pamplona, legitimaren el fet que els cabdills asturs de principis del segle VIII i els pamplonesos d'inicis del IX es proclamessin amb la dignitat de rex presentant-los com a successors directes -i descendents en un sentit biològic- dels reis gots dels segles VI i VII ${ }^{61}$. Una condició sine qua non, per tal de gaudir de la dignitat reial en bona part de l'Espanya cristiana dels segles X-XII, en la qual els reis i l'aristocràcia es reivindicaven com a gots ${ }^{62}$.

Doncs bé, aquesta legitimitat històrica goticista se la pogueren atribuir els reis pamplonesos i, sobretot, a través de la figura semillegendària del rei Pelai, els reis asturlleonesos i castellans, però no pas els comtes catalans dels segles XI i XII.

I és que, malgrat que en el segle IX i encara molt ocasionalment en el segle X els comtats ubicats entre els rius Roine i Llobregat -ara junts o ara per separat- pogueren ser identificats des de la cort franca o la mateixa Barcelona com a "Gòtia" ${ }^{63}$, els comtes sobirans de la pre-Catalunya no reivindicaren pas la connexió reial goda, ben segurament perquè eren conscients -i així ho testimonien els pergamins, cartularis i preceptes dels seus arxius- que la seva legitimitat històrica depenia d'uns avantpassats de la novena centúria designats pels carolingis ${ }^{64}$.

De fet, com exposa Cingolani, el neogoticisme fou propagat amb força arreu d'Espanya en el segle XIII per la crònica de l'arquebisbe de Toledo Rodrigo Jiménez de Rada. Tanmateix, no fou fins al segle XV que, amb l'entronització d'un Casal d'Aragó de llinatge castellanolleonès el 1412, es començà a reivindicar entre diversos sectors del principat de Catalunya els mateixos orígens i la mateixa legitimitat històrica goda que la Corona de Castella i Lleó ${ }^{65}$.

Segonament, si tractem sobre el període posterior a l'any 1137, pensem que l'explicació de la no-consecució del títol reial català pot radicar, bàsicament, en tres factors interns.

\footnotetext{
${ }^{61}$ Isla 2011.

${ }^{62}$ Isla 1995.

${ }^{63}$ Zimmermann 1989.

${ }^{64}$ Exposem el nostre agraïment al professor Amancio Isla per la seva generositat i gentilesa en guiar-nos en aquestes qüestions.

${ }^{65}$ Cingolani 2012, pp. 26-29; 2015, pp. 27-28.
} 
El primer és la falta de necessitat. Des de 1162 els comtes de Barcelona gaudiren de la dignitat règia que els conferia ser lo senyor rei d'Aragó, fet que de cara a l'exterior els equiparà nominalment a la resta de reis cristians ${ }^{66}$ i, de cara a l'interior, esdevingué el principal argument per a la consolidació del poder del comte barceloní com a sobirà de tot Catalunya, ja que la seva condició reial el situava per sobre dels altres comtes i nobles catalans ${ }^{67}$.

El segon factor és el caràcter políticament compost de la Catalunya medieval. Aquesta no nasqué directament com una unitat política compacta i tampoc de la unificació d'un conjunt de dominis territorials pertanyents tots al mateix príncep, com fou el cas d'Aragó ${ }^{68}$. Catalunya era el resultat de la suma de múltiples comtats independents entre ells, regits per diferents comtes que gaudien de la potestat suprema sobre els seus respectius comtats.

El declivi reial dels segles X i XI comportà arreu del regne franc occidental la patrimonialització de dominis territorials particulars per part de ducs i de comtes (com els dels comtats del nord-est ibèric) que la historiografia ha anomenat "principats territorials" ${ }^{69}$. Amb tot, cal dir que els dominis comtals de la pre-Catalunya eren geogràficament migrats en comparació amb els grans dominis territorials patrimonialitzats pels principals magnats francs: els ducs de Gascunya, de Bretanya, de Normandia, de Borgonya o el duc d'Aquitània i comte de Poitiers, per exemple. I si bé en aquelles centúries la preeminència del comte de Barcelona entre els comtes veïns era creixent, tant per raó de primogenitura entre els llinatges comtals descendents de Guifré el Pilós ${ }^{70}$ com, i sobretot, pel seu domini permanent sobre la triada comtal de Barcelona, Girona i Osona, aquest comte no unificà sota el seu poder els comtats catalans formant un gran senyoriu. La realitat política es traduí en l'existència oscil-lant d'entre quatre i set dominis comtals autònoms, que s'unien i dividien segons les herències. De fet, inclús a la fi del segle XII, quan la major part dels comtats catalans convergiren en el patrimoni familiar barceloní i aquest gaudí d'una gran ampliació territorial en l'espai català amb la conquesta dels territoris de Tortosa i Lleida, el bastiment geopolític de Catalunya es feu juxtaposant els dominis de diversos comtes.

En aquell període, Catalunya es conformà a partir dels comtats catalans del comte de Barcelona i rei d'Aragó més els comtats d’Urgell, Empúries i Pallars Sobirà que romanien encara sense formar part del domini de la Coro-

\footnotetext{
${ }^{66}$ Ferro 1999.

${ }^{67}$ Sabaté 1997.

${ }^{68}$ Aquest regne sorgí durant el segle XI de la conversió del petit comtat d'Aragó en regne, acabà de conformar-se en el segle XII amb la inclusió com a part d'aquest regne d'altres territoris veïns, com foren el comtat de Sobrarb o el regne de Saragossa, que eren tots ells dominis directes del rei aragonès i no pas de vassalls seus.

${ }^{69}$ Salrach 2011, p. 22.

${ }^{70}$ Abadal 1987, p. 63.
} 
na, car els comtes Pere, Sanç i Nunó Sanç de Rosselló i Cerdanya de finals del segle XII i inicis del XIII reberen del sobirà els seus comtats com a feus, per ser membres de la família reial catalanoaragonesa. Una tendència, la d'infeudar amb comtats de Catalunya infants secundogènits, que assoli un nou grau geopolític a la mort del rei Jaume I l'any 1276, quan l'infant Jaume no només rebé els comtats de Rosselló i Cerdanya, sinó també el regne de Mallorca i la senyoria de Montpeller. Així, tot i acabar esdevenint entre els segles XII i XIII vassalls del sobirà de Catalunya, el rei de Mallorca (pels comtats de Rosselló i Cerdanya), els comtes d'Urgell, d'Empúries, de Pallars Sobirà i el comte de Foix (que al territori català posseïa el vescomtat de Castellbó) no només gaudien d'una notable autonomia en els seus dominis senyorials, sinó que, a més a més, es podien equiparar al rei d'Aragó i comte de Barcelona, tant per posseir una prosàpia tan antiga i noble com la seva, com per gaudir del mateix rang comtal que el rei d'Aragó en allò que respectava a Catalunya.

El tercer factor, i potser el més influent, pensem que fou la voluntat de la classe dirigent catalana d'escurçar al màxim les diferències entre ella i el seu príncep sobirà. Abans i després de l'ascens barceloní al soli aragonès, els comtes, vescomtes, bisbes, abats, barons i castlans catalans eren molt reticents a sotmetre's al control del comte de Barcelona, i no pas perquè consideressin que aquest control podia ser lesiu al dret del rei francès, com sostenia d'Abadal, sinó contrari als seus propis drets particulars. En conseqüència, els membres de la revoltosa elit catalana dels segles XII i XIII es relacionaven amb el monarca catalanoaragonès segons els interessos que els impel-lien en cada moment. Tant el podien tractar com el seu senyor sobirà com també com a simple primus inter pares contra el qual podien rebel-lar-se amb relativa facilitat ${ }^{71}$.

Potser en aquesta dialèctica permanent entre el rei i la resta de la classe dirigent de Catalunya, encapçalada pels comtes emporità, urgellenc $\mathrm{i}$ pallarès i els vescomtes, s'entenen millor una tríada de fets del segle XIII.

D'una banda, tenim les reivindicacions cronístiques del seu títol i ascendència reial aragonesos que el mateix rei Jaume I feu exclusivament per a un públic català, ja que s'escrigueren en llengua catalana i sense cap pretensió que aquestes reflexions sortissin de Catalunya i, sobretot, de Barcelona ${ }^{72}$. I en aquest mateix sentit, no podem oblidar tampoc la voluntat de Pere II el Gran, frustrada el 1283, d'intitular-se exclusivament rei d'Aragó en la documentació i fer un únic acte de jurament de privilegis que servís per al conjunt de territoris de la Corona d'Aragó ${ }^{73}$.

${ }^{71}$ Sabaté 2005, pp. 483-498.

${ }^{72}$ Cingolani 2010 pp. 234-242; 2015, pp. 183-184.

${ }^{73}$ Ibidem, pp. 171-177. 
D'altra banda, trobem un subtil canvi en les Gesta per evitar afirmar que el comtat barcelonès fou obtingut a perpetuïtat per Guifré el Pilós i el seu llinatge amb les prerrogatives del poder regi. Cingolani ha percebut que si bé en la versió original de les Gesta, redactada entre 1180 i 1184, constava que el comtat de Barcelona havia arribat als seus comtes amb totes les prerrogatives de la potestat reial (cum potestate regali), poc abans de 1268 el "cum" fou substituït per un "de" (de potestate regali). Així, es modificà el significat de manera que ara el comte rebé el comtat no amb el poder reial, sinó directament i simplement del poder reial franc.

Llavors, partint de les tesis d'Abadal, la hipòtesi de Cingolani per comprendre aquest canvi és la següent: si bé el fet d'indicar que el comtat de Barcelona arribà als seus comtes amb (cum) les prerrogatives del poder reial encaixa amb la construcció d'una autoritat "estatal" en temps d'Alfons I el Cast, un cop signat el tractat de Corbeil per Jaume I, el que es volgué destacar és que la potestat dels comtes barcelonins provenia, ara de dret i no només de fet, del rei francès ${ }^{74}$.

Tanmateix, com hem pogut comprovar, el tractat del Corbeil no fou concebut com a justificant jurídic d'unes independències de fet del comtats catalans del segle X. A més, en totes les versions de les Gesta (ss. XII-XIII) s'explica que el monarca franc concedí el comtat de Barcelona a Guifré i al seu llinatge perpètuament per expulsar els musulmans sense ajuda. Així, doncs, ja des de la versió primitiva del segle XII es considera que els comtes de Barcelona posseeixen el comtat de fet, però també de dret, des dels temps de Guifré I.

Per tant, al nostre parer, el subtil canvi pot tenir quelcom a veure amb l'existència d'altres comtes catalans en la segona meitat del segle XIII i no guardar relació amb el rei de França. A partir de la lectura de les Gesta sense el canvi de cum per de, comtes com els d'Urgell, Empúries o Pallars podrien haver adduït que els seus antecessors en el càrrec comtal també havien posseït dels respectius comtats amb (cum) el poder reial i havien exercit de sobirans autònoms. Un argument que els podria haver servit per equiparar-se, encara més, al comte de Barcelona i rei d'Aragó en el marc de Catalunya.

En canvi, si en les Gesta el comte Guifré I rebia Barcelona/Catalunya del $(d e)$ poder reial franc, en la segona meitat del segle XIII -ja extingida la dinastia barcelonina de Rosselló i Cerdanya i havent passat aquests comtats al domini del sobirà catalanoaragonès, així com finida també la dinastia comtal urgellenca que descendia de Guifré i romanent el comtat en poder dels

${ }^{74}$ Cingolani 2008, p. 173. 
Cabrera-, només el rei Jaume I podia proclamar-se hereu i successor directe i exclusiu del Pilós.

Dit això, existeixen una altra tríada de fets que semblen confirmar les nostres hipòtesis en relació al període posterior a la unió catalanoaragonesa dels anys 1137-1162:

En primer lloc, l'esmentada creació dels regnes de Mallorca (1229) i València (1238) amb la seva legalitat privativa. La historiografia indica que si Jaume I erigí aquests nous dominis com a regnes autònoms, i no com a noves regions de Catalunya o d'Aragó, fou per tal de controlar-los millor i extreure'n molt més rendiment. Llavors, per què aquest rei no prengué per si mateix el títol de rex Cathalonie, ni tan sols després del tractat de Corbeil? Doncs perquè la classe dirigent catalana -de la qual els reis depenien per finançar les seves múltiples guerres i per controlar el país-, n'era l'autèntic impediment, com advertí el mateix d'Abadal quan esmentà de passada, en fer al·lusió al problema polític que suscitarien al rei Jaume I les probables reticències que acompanyarien una proclamació especial de la condició reial oficial per a Catalunya ${ }^{75}$.

En segon lloc, cal recordar que foren els tres braços estamentals catalans que, aprofitant la crisi i debilitat règia a causa de la guerra contra el Papat, Nàpols i França arran de la conquesta catalanoaragonesa de Sicília (1282), feren sancionar per llei, en les Corts de Catalunya de 1283, que el rei Pere II $i$ els seus successors no podrien emprar de forma oficial a Catalunya cap altra titulació que no fos la comtal barcelonina ${ }^{76}$. Fet que demostra la voluntat de la classe dirigent catalana d'evitar el distanciament jeràrquic, ni que fos formal, entre el rei i l'alta noblesa comtal (Rosselló i Cerdanya, Urgell, Empúries, Pallars i Foix) del país.

En tercer lloc, hem de tenir en compte el procés judicial que el rei Pere III el Cerimoniós incoà contra el rei Jaume III de Mallorca l'any 1343 per arrabassar-li el regne de Mallorca i els comtats de Rosselló i Cerdanya. Cal posar de manifest que quan el rei Pere III reivindicà la seva condició de sobirà i la seva jurisdicció suprema sobre Catalunya, no se serví dels mots "rei" i "regne", sinó dels termes "príncep" i "principat", fet que segurament té molta més relació amb les elits catalanes i la prohibició legal imposada per les Corts de l'any 1283 , que no pas amb cap poder extern.

${ }^{75}$ Abadal 1987, p. 67.

${ }^{76}$ Sabaté 1997, p. 341. 


\section{CONCLUSIÓ}

En el present article s'ha demostrat la manca de viabilitat de la teoria clàssica de Ramon d'Abadal sobre el fet que la Catalunya medieval no adquirí oficialment la categoria de "regne" i sí de "principat", perquè fins a la signatura del tractat de Corbeil (any 1258), legalment el rei de Catalunya era el rei de França. Una concepció que es fonamentà de forma descontextualitzada (i errònia en el cas particular de Pere Miquel Carbonell) en tesis d'autors dels segles XV, XVI i XVII, les quals foren modernitzades per d'Abadal adaptant-les anacrònicament als paràmetres geopolítics dels segles XIX i XX. El desballestament d'aquesta explicació tradicional de d'Abadal -la vàlua historiogràfica del qual, fora de la temàtica que ens ocupa, no hem volgut en cap cas menystenir- permet el retorn d'aquesta qüestió històrica a la palestra historiogràfica. Finalment, després de repassar les darreres interpretacions històriques sobre els fets clau de les relacions de la reialesa francesa amb el poder comtal barceloní entre finals del segle X i mitjan del XII, així com també sobre el tractat de Corbeil, pensem que les hipòtesis plantejades en el darrer apartat ofereixen la possibilitat d'analitzar la documentació dels segles IX-XIV des dels múltiples enfocaments de la història política (pensament polític, anàlisi conceptual dels termes juridicopolítics i la comparativa amb l'evolució política dels països veïns...) que poden ajudar a respondre, de manera més aproximada a la realitat històrica medieval, al perquè del fet que Catalunya fou oficialment un "principat" i no un "regne".

\section{BIBLIOGRAFIA CITADA}

FONTS PRIMÀRIES (NO ARXIVÍSTIQUES)

Jaume I d'Aragó, Llibre dels feyts del rei en Jaume, ed. Ferran Soldevila (reed. pòstuma), Barcelona, Institut d'Estudis Catalans, 2007.

Pere III d'Aragó, Crònica General de Pere III el Cerimoniós, dita comunment Crònica de Sant Joan de la Penya, ed. Amadeu-J. Soberanas, Barcelona, Alpha, 1961.

Beuter, Pero Anton, Segunda parte de la Coronica general de España, y especialmente de Aragón, Cathaluña y Valencia,València, Joan de Mey, 1551. [Consultable a Biblioteca Valenciana Digital].

Bofarull, Manuel de (ed.) (1866), Colección de documentos inéditos, 30, Barcelona, imprenta del archivo.

Carbonell, Pere Miquel, Cròniques d'Espanya, ed. Agustí Alcoberro, 2 vols., Barcelona, Barcino, 1997. 
Desclot, Bernat (2009), Libre del rei en Pere e de sus antecesors passats, ed. Stefano M. Cingolani, Barcelona, Barcino.

Gestes dels comtes de Barcelona i reis d'Aragó, ed. Stefano Maria Cingolani, (2012), Santa Coloma de Queralt, Obrador Edèndum.

Laborde, M. Joseph de (ed.) (1873), Layettes du Trésor des chartes, tom 3, París, Plom, pp. 405-408.

Pujades, Jeroni (1829-1832), Crónica Universal del principado de Cataluña, 8 vols., Barcelona, José Torner [consultable a Google Books].

Albert, Ricard; Gassiot, Joan (eds.) (1928), Parlaments a les Corts Catalanes, Barcelona, Barcino.

\section{REFERÈNCIES BIBLIOGRÀFIQUES}

Abadal, Ramon d' (1965), Els Primers comtes catalans, Barcelona, Vicens Vives (1 a ed., Teide, 1958).

Abadal, Ramon d' (1987), Pere el Cerimoniós i els inicis de la decadència política de Catalunya, Barcelona, Edicions 62 (1 $1^{\mathrm{a}}$ ed., pòstuma 1972).

Abadal, Ramon d' (1997), Catalunya fa mil anys: notes històriques en ocasió del mil-lenari, Barcelona, Generalitat de Catalunya (ed., pòstuma).

Belenguer, Ernest (2007), Jaume I i el seu regnat, Lleida, Pagès.

Benito i Monclús, Pere (2009), L'expansió territorial ultrapirinenca de Barcelona i la Corona d'Aragó: guerra, política i diplomàcia (10671213), a Ferrer i Mallol, Maria Teresa; Rius, Manuel (dirs.), Tractats $i$ negociacions diplomàtiques de Catalunya $i$ de la Corona catalanoaragonesa a l'edat mitjana, Barcelona, Institut d'Estudis Catalans, vol. $1 / 1$, pp. 13-150.

Cingolani, Stefano Maria (2007), Jaume I. Història i mite d'un rei, Barcelona, Edicions 62.

Cingolani, Stefano Maria (2008), Estratègies de legitimació del poder comtal: l'abat Oliba, Ramon Berenguer I, la Seu de Barcelona i les Gesta Comitum Barchinonensium, "Acta historica et archaeologica mediaevalia" 29, pp. 135-175.

Cingolani, Stefano Maria (2010), Tradiciones e idiosincrasias. Las relaciones entre Cataluña y Aragón en la historiografía (siglos XI-XIII), a Sesma, José Ángel (coord.), La Corona de Aragón en el centro de su Historia. 1208-1458. La Monarquía aragonesa y los reinos de la Corona, Saragossa, Gobierno de Aragón, pp. 219-252.

Cingolani, Stefano Maria (2012), Introducció, a Cingolani, Stefano Maria (ed.), Gestes dels comtes de Barcelona i reis d'Aragó. Gesta Comitum Barchinone et Regum Aragonie, Santa Coloma de Queralt, Obrador Edèndum, pp. 11-53. 
Cingolani, Stefano Maria (2015), La formació nacional de Catalunya i el fet identitari dels catalans (785-1410), Barcelona, Generalitat de Catalunya.

Ferran, Elisabet (2001), El Jurista Pere Albert i les Commemoracions, Barcelona, Universitat Pompeu Fabra (tesi doctoral).

Ferrando, Antoni (1980), Consciència idiomàtica i nacional dels valencians, València, Universitat de València.

Ferro, Víctor (1999), Dret públic català: les institucions a Catalunya fins al Decret de Nova Planta, Vic, Eumo (1 ${ }^{\text {a }}$ ed. 1987).

Font i Rius, Josep M.; Mundó, Anscari M.; Riu i Riu, Manuel; Udina i Martorell, Frederic; Vernet i Ginés, Joan (1989), Procés d'independència de Catalunya (ss. VIII-XI). La fita del 988, Barcelona, Generalitat de Catalunya, Comissió del Mil-lenari del naixement polític de Catalunya.

Garrido Valls, Josep-David (2014), Ramon Berenguer IV, Barcelona, Rafael Dalmau.

Isla, Amancio (1995), Consideraciones sobre la monarquía Astur, "Hispania. Revista española de historia" 189, pp. 151-168.

Isla, Amancio (2011), La construcción de la monarquía en León, siglos X y XI: historias y leyes, a Martínez Sopena, Pascual; Rodríguez, Ana (eds.), La construcción medieval de la memoria regia, València, $\mathrm{Pu}-$ blicacions de la Universitat de València, pp. 33-44.

Lalinde, Jesús (1997), Depuración histórica del concepto de Corona de Aragón, a Sarasa, Esteban; Serrano, Eliseo (coords.), La Corona de Aragón y el Mediterráneo: siglos XV-XVI, Zaragoza, Institución Fernando el Católico, pp. 433-458.

Maravall, José Antonio (1954), Sobre el sistema de datación por los reyes francos en los diplomas catalanes, "Revista de Archivos, Bibliotecas y Museos" 60, pp. 361-374.

Narbona, Rafael (2015), En l'horitzó de la història ibèrica. Pobles, terres, sobiranies (segles V-XV), Catarroja, Afers.

Palomo, Cristian (2018a), Identitat i vocabulari polítics a Catalunya durant la Guerra de Successió, Bellaterra, Universitat Autònoma de Barcelona (tesi doctoral inèdita).

Palomo, Cristian (2018b), A propòsit de de les teories de la creació de la Corona d'Aragó mitjançant el "casamiento en casa" i l'extinció del llinatge barceloní el 1137, "Revista de Dret Històric Català" 17, pp. 11-58.

Sabaté, Flocel (1997), El territori de la Catalunya medieval: percepció de l'espai i divisió territorial al llarg de l'edat mitjana, Barcelona, Rafael Dalmau.

Sabaté, Flocel (2005), El poder soberano en la Cataluña bajomedieval: definición y ruptura, a Foronda, François; Genet, Jean-Philippe; Nieto, 
José Manuel (dirs.), Coups d'État à la fin du Moyen Âge? Aux fondements du pouvoir politique en Europe occidentale, Madrid, Casa de Velázquez, pp. 483-527.

Sabaté, Flocel (2010), La Catalunya dels segles X-XII i la definició historiogràfica del feudalisme, "Catalan Historical Review" 3, pp. 163-184.

Salrach, Josep Maria (2011), Legitimación del poder condal en los orígenes de Cataluña, a Martínez Sopena, Pascual; Rodríguez, Ana (eds.), La construcción medieval de la memoria regia, València, Publicacions de la Universitat de València,pp. 21-32.

Sobrequés, Jaume (2015), Consolidació i majoria d'edat del fet identitari català (1410-1714), Barcelona, Generalitat de Catalunya.

Soldevila, Ferran (1962), Història de Catalunya, 3 vols., Barcelona, Alpha. Villacañas, José Luis (2003), Jaume I el Conquistador, Madrid, Espasa Calpe. Villanueva, Jesús (1994), Los orígenes carolingios de Cataluña en la historiografía y el pensamiento político del siglo XVII, Bellaterra, Universitat Autònoma de Barcelona (tesina).

Zimmermann, Michel (1989), En els orígens de Catalunya: emancipació política y afirmació cultural, Barcelona, Edicions 62.

Zimmermann, Michel (1991), Hugues Capet et Borrell. Á propos de l'independence de la Catalogne, a Barral, Xavier (dir.), Catalunya i França meridional a l'entorn de l'any Mil. Actes del col-loqui internacional Hug Capet, Barcelona, Generalitat de Catalunya, pp. 59-64.

Fecha de recepción artículo: mayo 2019

Fecha de aceptación y versión final: octubre 2019 